${ }^{1}$ Dr. Rowshan Jahan Akhter Medical Officer

Dept. of Neonatology

Dhaka Shishu (children) Hospital

${ }^{2}$ Prof. Dr. Md. Mahbubul Hoque

Professor

Dept. of Neonatology

Dhaka Shishu (children) Hospital

\& Bangladesh Institute

of Child Health (BICH)

3 Prof. Dr. B H Nazma Yasmeen

Professor \& Head

Dept. of Pediatrics

Northern International Medical

College, Dhaka

${ }^{4}$ Prof. Dr. M A K Azad Chowdhury

Professor \& Head

Dept. of Neonatology

Dhaka Shishu (children)

Hospital \& BICH

Correspondence

Dr. Rowshan Jahan Akhter

Medical Officer

Dept. of Neonatology

Dhaka Shishu (children) Hospital

email: rowshanfairuz22@gmail.com

\title{
Bacteriological profile and sensitivity pattern of neonatal sepsis
}

\section{R J Akhter ${ }^{1}$, M M Hoque ${ }^{2}$, B H N Yasmeen ${ }^{3}$, M A K A Chowdhury ${ }^{4}$}

\section{Abstract}

Introduction: Neonatal sepsis remains an important cause of neonatal morbidity and mortality in NICU setup and a major challenge for the neonatologists. The prevalent organisms and their antibiotic resistance patterns evolve with time and with the usage of antimicrobials.

Aims and Objectives: To analyze the bacteriological profile and antibiotic resistance patterns of proven neonatal sepsis cases in Dhaka Shishu Hospital.

Materials and Methods: The study was Prospective observational study. All the clinically suspected cases of Neonatal Sepsis admitted to the Neonatal word from January 2015 to December 2015 were included in the study. Clinically suspected cases of neonatal sepsis further evaluated with blood cultures and antibiotic susceptibility testing using the Kirby Bauer disc diffusion method. Data was collected for the following variables: Demographic profile, haematological profile, blood culture result and antibiotic sensitivity patterns.

Results : Total 96 cases clinically suspected neonatal sepsis were included in the study. Among them 29 cases $(30.21 \%)$ was culture positive septicemia. Klebsiella pneumoniae was the most common isolate accounting for $31.03 \%$ cases followed by Escherichia coli $27.59 \%$. In Klebsiella infection most common sensitivity were Imipenum and Ciprofloxacin which were 77.78 and $33.33 \%$ respectively. In E.coli common sensitive drugs were Imipenum and Amikacin. In serratia common sensitive drugs were Imipenum, NetImicin and Ciprofloxacin.

Conclusion: K. pneumoniae was the most common pathogen. Most common sensitivity was Imipenum, Amikacin, Ciprofloxacin, Gentamicin, Netlmicin, and Ceftazidime,.

Northern International Medical College Journal Vol. 8 No. 01 July 2016, Page 174-177

\section{Introduction}

Neonatal sepsis is defined as systemic inflammatory response syndrome caused by suspected or proven infection occurring within the first 28 days of life. ${ }^{1}$ Neonatal septicemia is responsible for approximately $25 \%$ of the neonatal deaths in the world and mostly in developing countries. ${ }^{2,3}$ Increased prevalence of extended spectrum beta-lactamases (ESBLs) and methicillinresistant Staphylococcus aureus (MRSA) and multiple drug resistant (MDR) strains is a cause of concern in Neonatal Intensive Care Units (NICU) worldwide. Septicemia has been classified as early onset septicemia (EOS) and late-onset septicemia
(LOS). ${ }^{4}$ The microorganisms most common associated with EOS include Group B Streptococcus (GBS), Escherichia coli, coagulase negative Staphylococcus species (CONS), Haemophilus influenzae and Listeria monocyto-gene. ${ }^{5}$ and LOS is caused by CONS, S.aureus, E.coli, Klebsiella spp., Pseudomonas spp., Enterobacter spp., Candida spp.,GBS, Serratia spp., Acinetobacter spp. and anaerobes. The recent trends show an increase in infections due to CONS. 6

The clinical diagnosis of neonatal septicemia is difficult as it presents with non-specific signs and symptoms. An early diagnosis of neonatal septicemia is 
important to initiate appropriate and prompt treatment. The correct and timely identification of infectious agents and their antibiotic sensitivity patterns are essential to guide the clinicians regarding both the empirical and definitive treatment. ${ }^{7}$ In this study we analyzed the bacteriological profile in neonatal septicemia and their antibiotic sensitivity pattern.

\section{Material and methods}

This was a prospective observational study conducted in the Department of Neonatology, Dhaka Shishu (Children) Hospital. All the clinically suspected cases of Neonatal Sepsis admitted to the Neonatal word from January 2015 to December 2015 were included in the study. Neonatal sepsis was clinically suspected if a neonate presented with the clinical signs and symptoms of Neonatal sepsis and with positive history of high risk factors in mother such as-

- Chorioamniotis

- prolonged rupture of membrane $>24$ hours

- meconium stained or foul smelling liquor during labour

- presence of urinary tract infection, more than 3 or unclean vaginal examination during labour

- those babies who needed active resuscitation at the time of birth.

Total 96 cases clinically suspected neonatal sepsis were included in the study. Blood cultures were taken in all the clinically suspected cases. Empirical antibiotic therapy was started in all the cases. Demographic profile (age, sex and birth weight), haematological parameters etc. were properly recorded and tabulated in chart. The Blood samples were collected from peripheral vein using strict aseptic precautions. Sampling site was cleansed with 70 $\%$ alcohol and $1 \%$ povidone iodine followed by alcohol. 2 $\mathrm{ml}$ of blood was collected in a single blood culture bottle (20 $\mathrm{ml}$ of brain heart infusion broth with $0.025 \%$ sodium polyethanol sulfonate as anticoagulant) and sent for microbiological examination. The Samples were incubated at $37^{\circ} \mathrm{C}$ for 7 days. Subcultures were done on blood agar, Mac Conkey and Chocolate medium on appearance of turbidity on days 1, 2, 3 and 7. Organisms were identified according to the standard microbial procedures including gram stain, colony morphology, motility and biochemical reactions. Antimicrobial susceptibility testing was done using Kirby Bauer disc diffusion method on Mueller Hinton agar as per CLSI guidelines.

\section{Results}

Total 96 cases clinically suspected neonatal sepsis were included in the study. The mean age was $8.33 \pm 7.36$ days, mean birth weight was $2816.25 \pm 288.6 \mathrm{gm}$, male were predominant which was $68.75 \%$ (Table I).

$\begin{array}{lcc}\text { Table I: Demographic characteristics of the study population } \\ \text { Parameters } & \text { Mean } \pm \text { SD } & \text { Range } \\ \text { Age (days) } & 8.33 \pm 7.36 & 1-20 \\ \text { Weight (gm) } & 2816.25 \pm 288.6 & 1500-3420 \\ \text { Sex } & \text { No. } & \text { Percentage } \\ \text { - Male } & 66 & 68.75 \% \\ \text { - Female } & 30 & 31.25 \%\end{array}$

In this study out of 96 cases 29 cases were culture positive septicemia which was $30.21 \%$ (Table II).

\section{Table II: Blood culture findings}

$\begin{array}{lcc}\text { Blood culture } & \text { Number } & \text { Percentage } \\ \text { Culture positive } & 29 & 30.21 \\ \text { Culture negative } & 67 & 69.79 \\ \text { Total } & 96 & 100.00\end{array}$

In this series Klebsiella was the commonest isolate, accounting for about $31 \%$ of neonatal septicaemia. The second commonest isolate was E.coli, which was seen in $27.59 \%$ of cases. The Serratia, Acintobacter and Pseudomonas isolates were also seen in about 24\%, $10.34 \%$ and $6.90 \%$ of cases respectively (Table III).

Table III: Isolated organism of culture positive cases $(n=29)$

\section{Organism}

Klebsiella pneumoniae

Escherichia coli

Serratia

Acintobacter

Pseudomonas
Number

09

08

07

03

02
Percentage

31.03

27.59

24.14

10.34

6.90
In E.coli common sensitive drugs were Imipenum, Amikacin, Ciprofloxacin, Netlmicin, Ampicillin and Gentamicin which were $100 \%, 75 \%, 62.5 \%, 50 \%$, respectively. In Klebsiella most common sensitivity were Imipenum and Ciprofloxacin which were $77.78 \%$ and $33.33 \%$ respectively. In Acinatobecter common sensitivity were Amikacin, Gentamicin, Ceftazidime, Imipenum and Netlmicin which were $100.0 \%, 66.67,66.67,66.67$ and $66.7 \%$ respectively. In serratia common sensitive drugs were Imipenum, Netlmicin and Ciprofloxacin which were 100.0\%, 57.14 and 
$42.86 \%$ respectively. Pseudomonas was found $50.0 \%$ sensitive to Ceftazidime, Amikacin, Ciprofloxacin, Imipenum, NetImicin and Ceftriaxone (Table IV).

\begin{tabular}{|c|c|c|c|c|c|c|c|c|c|c|}
\hline \multirow{2}{*}{$\begin{array}{l}\text { Iable IV: Se } \\
\text { Organism } \\
\text { Total=29 blooc } \\
\text { culture positive }\end{array}$} & \multicolumn{2}{|c|}{ E.coli } & \multicolumn{2}{|c|}{ Klebsiella } & \multicolumn{2}{|c|}{ Acintobacter } & \multicolumn{4}{|c|}{ Serratia Pseudomonas } \\
\hline \multicolumn{11}{|l|}{ Total $=29$ blood } \\
\hline & $n=8$ & $(\%)$ & $n=9$ & $(\%)$ & $n=3$ & $(\%)$ & $n=7$ & $(\%)$ & $n=2$ & $(\%)$ \\
\hline mpicillin & 03 & 37.5 & 00 & 0.00 & 00 & 0.00 & 00 & 0.00 & 00 & 00 \\
\hline entamicin & 03 & 37.5 & 02 & 22.22 & 02 & 66.67 & 00 & 0.00 & 00 & 00 \\
\hline Ceftazidime & 02 & 25 & 02 & 22.22 & 02 & 66.67 & 00 & 0.00 & 01 & 50 \\
\hline mikacin & 06 & 75 & 02 & 22.22 & 03 & 100.0 & 00 & 0.00 & 01 & 50 \\
\hline Ciprofloxacin & 05 & 62.5 & 03 & 33.33 & 01 & 33.33 & 03 & 42.86 & 01 & 50 \\
\hline nipenum & 08 & 100 & 07 & 77.78 & 02 & 66.67 & 07 & 100 & 01 & 50 \\
\hline etlmicin & 04 & 50 & 02 & 22.22 & 02 & 66.67 & 04 & 57.14 & 01 & 50 \\
\hline trimaxazole & 02 & 25 & 02 & 22.22 & 01 & 33.33 & 00 & 0.00 & 00 & 00 \\
\hline triaxone & 02 & 25 & 02 & 22.22 & 01 & 33.33 & 00 & 0.00 & 01 & \\
\hline
\end{tabular}

\section{Discussion}

Neonatal septicaemia is one of the leading causes of neonatal mortality in developing countries like Bangladesh and India. The bacteriological profile of neonatal sepsis varies from place to place and from time to time. ${ }^{8}$

In this study, about $30.21 \%$ cases with suspected neonatal septicemia had positive blood culture. A review showed that, positive culture ranged from $8 \%$ to $73 \%$ in the diagnosis of potential sepsis. ${ }^{9,10}$ Our result is almost similar to the study of Haque et al, Mathur $M$ et al and comparable to Mondol JP et al. ${ }^{11,12}$

In this series Klebsiella was the commonest isolate, accounting for about $31 \%$ of neonatal septicaemia. The second commonest isolate was E.coli, which was $27.59 \%$. The Serratia, Acintobacter and Pseudomonas isolates were also seen in about $24 \%, 10.34 \%$ and $6.90 \%$ of cases respectively. Comparable with the study of Singh et al, they found Klebsiella pneumoniae was the most common isolate accounting for $49.64 \%$ cases followed by Escherichia coli $26.95 \%$, Pseudomonas aeruginosa $7.80 \%$, and Staphylococcus aureus $7.09 \%$, same as the results of earlier studies. ${ }^{13-15}$ In the study of Kumaravel et al. showed that among the isolates, Klebsiella was the most common organism followed by Escherichia and Pseudomonas. ${ }^{8}$ Many other studies have also reported Klebsiella as the most common isolate. ${ }^{16}$ The National Neonatal Perinatal database also states Klebsiella as the most common (29\%) pathogen in neonatal septicaemia. ${ }^{17}$

The other studies done by Aletayeb et al, Shrestha et al, and Jyothi et al. showed that K. pneumoniae, S.aureus and coagulase negative Staphylococci were the predominant organisms for neonatal sepsis. ${ }^{15,} 18,19$

Bhat et al found that $S$. aureus was the predominant organism for neonatal sepsis. ${ }^{20}$ Mhada et al Shahian et al. and Dias et al reported coagulase-negative Streptococci as the major organisms for neonatal sepsis in their studies. ${ }^{21,22}$

In our study E.coli had sensitivity to Imipenum, Amikacin, Ciprofloxacin and Netlmicin, which were 100\%, 75\%, $62.5 \%, 50 \%$ respectively. In Klebsiella most common sensitivity were Imipenum and Ciprofloxacin which were $\mathbf{7 7 . 7 8 \%}$ and $33.33 \%$ respectively. In Acinatobecter common sensitivity were Amikacin, Gentamicin, Ceftazidime, Imipenum and Netlmicin which were $100.0 \%, 66.67,66.67,66.67$ and $66.7 \%$ respectively. Serratia was sensitive to Imipenum, Netlmicin and Ciprofloxacin which were $100.0 \%, 57.14$ and $42.86 \%$ respectively. In Pseudomonas $50.0 \%$ sensitivity was found in Ceftazidime, Amikacin, Ciprofloxacin, Imipenum, Netlmicin and Ceftriaxone. Klebsiella was sensitive to ciprofloxacin shown in the studies done by Kayange et al and Aletayeb et al. ${ }^{15,23}$

In this study most of the strains showed a low sensitivity to Amikacin (14.94\%), Gentamicin (14.29\%) and Cefotaxime $(4.55 \%)$. When compared with the other studies Cefotaxime was found less sensitive in our study. ${ }^{18,19,21}$ Study done by Singh et al showed that S. aureus was highly resistant to Ampicillin (80 \%) which was similar to the results of some other studies. ${ }^{14,24}$ In this study varying levels of resistance was also found against Co-trimoxazole (60\%) and 3rd generation Cephalosporins (10\%).

\section{Conclusion}

K. pneumoniae was the most common pathogen of Neonatal septicaemia. Most common sensitivity found to Imipenum, Amikacin, Ciprofloxacin and Netimicin.

\section{References}

1. Maria Annette Enrione, Keith R, Powell. Sepsis, Septic shock and Systemic Response Syndrome. In: Kleigman RM, editor. Nelson Textbook of Pediatrics. Philadelphia: W.B.Saunders, 18th ed, 2008; 1094.

2. Aftab R, Iqbal I. Bacteriological agents of neonatal sepsis in NICU at Nishtar hospital, Multan. J Coll Physicians Surg Pak. 2006; 16(3): 216-9.

3. WHO|Newborns: Reducing Mortality. WHO. Available from: Error! Hyperlink reference not valid.. [Last cited on 2013 May 25]. 
4. WHO | Levels and Trends in Child Mortality. WHO. Available from: http://www.who.int/maternal_child adolescent/documents/ levels_trends_child_mortality_2012/ en/index.html.[Last cited on 2013 May 25

5. Ballot DE, Nana T, Sriruttan C, Cooper PA. Bacterial bloodstream infections in neonates in a developing country. ISRN Pediatr 2012;2012:508512

6. Hornik CP, Fort P, Clark RH, Watt K, Benjamin DK Jr, Smith PB, et al. Early and late onset sepsis in very-low-birth-weight infants from a large group of neonatal Intensive Care Units. Early Hum Dev 2012;88 Suppl 2:S69-74

7. Thakur S, Thakur K, Sood A, Chaudhary S. Bacteriological profile and antibiotic sensitivity pattern of neonatal septicaemia in a rural tertiary care hospital in North India. Indian J Med Microbiol [serial online] 2016 [cited 2016 Sep 6];34:67-71.

8. Kumaravel K S, Rameshbabu B. A study of the bacteriological profile and antibiotic sensitivity in neonatal septicemia. International Journal of Contemporary Medical Research 2016;3(6):1830-1831.

9. Buttery JP. Blood culture $s$ in neoborns and children: optimizing in everyday test. Arch Dis Child Fetal Neonatal 2002;87:25-28.

10. Cheisa C, Pellegrini G, Panero A. C-reactive protein, Interleukin6 , and procalcitonin in the immediate postnatal period : influence of illness severity, risk status, antenatal and perinatal complications and infection. Clin Chem 2003; 49: 60-68

11. Haque MF, Safiquzzaman SM, Salim AFM, Monzur F, Banu SH. Bacteriological profile of neonatal septicemia in a Special Care Neonatal Unit (SCANU). DS (Child) H J 2008; 24 (1 \& 2) : 4-8

12. Mathur M, Shah $H$, Dixit K, Khambadkone $S$, Chakrapani $A$, Irani S. Bacteriological profile of neonatal septicemia cases( for the year 1990-91).J Postgrad Med 1994;40:18-20.

13. Kenneth C Iregbu, Olumilayo Y Elegba and Iretiola B Babaniyi. Bacteriological profile of neonatal septicaemia in a tertiary hospital in Nigeria. Afr Health Sci 2006; 6(3): 151-154.

14. Singh HK, Sharja $P$, and Onkar K. Bacteriological profile of neonatal sepsis in neonatal intensive care unit (nicu) in a tertiary care hospital: Prevalent bugs and their susceptibility patterns. ejpmr, 2016; 3(3), 241-245
15. Aletayeb SMH, Dokht Khosravi AD, Dehdashian M, Kompani $F$, Mortazavi SM and Aramesh MR. Identificaion of bacterial agents and animicrobial suscepibility of neonatal sepsis: A 54-month study in a tertiary hospital. African Journal of Microbiology Research 2011; 5(5): 528-53.

16. Mathur M, Shah H, Dixit K, Khambadkone S, Chakrapani A, Irani S. Bacteriological profile of neonatal septicemia cases. J Postgrad Med. 1994;40:18-20.

17. Neonatal morbidity and mortality; report of the National NeonatalPerinatal Database. Indian Pediatr. 1997;34:1039 42.

18. Shrestha S, Shrestha NC, Dongol Singh S, Shrestha RP, Kayestha S, Shrestha M, et al. Bacterial isolates and its antibiotic susceptibility pattern in NICU. Kathmandu Univ Med J (KUMJ) 2013;41(1):66-70.

19. Jyothi P, Basavaraj MC, Basavaraj P. Bacteriological profile of neonatal septicemia and antibiotic susceptibility pattern of the isolates. J Nat Sci Biol Med 2013;4(2):306-9.

20. Bhat $R$, Lewis LE, Vandana KE. Bacterial isolates of early-onset neonatal sepsis and their antibiotic susceptibility pattern between 1998 and 2004: An audit from a center in India. Ital J Pediatr 2011;37(32):512-7.

21. Shahian M, Pishva N, Kalani M. Bacterial etiology and antibiotic sensitivity patterns of early-late onset neonatal sepsis among newborns in Shiraz, Iran 2004-2007. IJMS 2010;35(4):293-8.

22. Dias $E$, Brain $P$. The bacterial profile of neonatal septicaemia in a rural hospital in South India. J Clin Diagn Res 2010;4:3327-30.

23. Kayange N, Kamugisha E, Mwizamholya DL, Jeremiah S, Mshana SE. Predictors of positive blood culture and deaths among neonates with suspected neonatal sepsis in a tertiary hospital, Mwanza-Tanzania. BMC Pediatr 2010;10:39.

24.Kaistha N, Mehta M, Singla N, Garg R, Chander J. Neonatal septicemia isolates \& resistance pattern in a Tertiary care Hospital of North India. J Infect Dev Ctries.2009; 41: 55-7. 